\title{
Comparative Evaluation of Conventional Rotary Technique with Piezoelectric Technique in Removal of Impacted Third Molar
}

\author{
Dushyanth, B. Pavan Kumar, V. Vidya Devi, V. Venkatesh, P. Praveen \\ Department of Oral and Maxillofacial Surgery, Kamineni Institute of Dental Sciences, Narketpally, Telangana, India
}

Email for correspondence: pavankumarbatchu40@gmail.com

\begin{abstract}
Context: Surgical removal of impacted third molars is often required to prevent clinical symptoms. While rotary cutting instruments have been traditionally and are still popularly used to remove impacted third molars, they are associated with high rate of pain and post-operative swelling. Piezosurgery is a newer technique that promises greater precision of cuts and lesser post-operative sequelae. Aims and Objectives: The aim of the present study was to compare the piezosurgery with rotary techniques in terms of their intraoperative and post-operative effects. Materials and Methods: A total of 40 patients, within the age of 18-40 years, with asymptomatic impacted mandibular third molars, were selected for the study and randomized into two groups. Group A consisted of 20 patients who underwent surgical extraction with rotary instruments and Group B consisted of 20 patients who underwent surgical extraction done with piezoelectric unit. The intraoperative time taken and tissue destruction was assessed and the post-operative pain, swelling, and trismus were assessed over a follow-up period of 7 days. Results: The mean time of surgery was $27.35 \pm(3.1)$ min in Group A, whereas it was $53.65 \pm(2.4)$ min in Group B. The mean incidence of tissue destruction was $0.8000 \pm(0.41)$ in Group A, whereas it was $0.2000 \pm(0.41)$ in Group B. The mean postoperative pain on day 0 was 5.05 $\pm(0.69)$ in Group A and 3.05 $\pm(0.69)$ in Group B, on day 3 was 3.20 $\pm(0.7)$ in Group A and $1.50 \pm(0.69)$ in Group B, and on day 5 was $2.0 \pm(0.73)$ in Group A and $0.40 \pm(0.6)$ in Group B. On the $3^{\text {rd }}$ postoperative day, mean post-operative swelling $2.51 \pm(0.3) \mathrm{cm}$ in Group A and mean post-operative swelling $1.2600 \pm$ $(0.28910) \mathrm{cm}$ in Group B. On the $5^{\text {th }}$ post-operative day, mean post-operative swelling was $1.4 \pm(0.31)$ in Group A and $0.5650 \pm(0.21095)$ in Group B. The difference between both groups was found to be statistically significant for all parameters. Conclusion: Although piezosurgery takes more time and is more expensive, the advantages gained in terms of tissue preservation, and decreased pain and swelling make it a superior technique compared to using rotary instruments in impacted third molar.
\end{abstract}

Key words: Impaction, piezosurgery, rotary, third molar

\section{INTRODUCTION}

Impacted third molars are frequently reported in clinical practice, with a prevalence of $33-58.7 \%$ and are well documented to be associated with several

Quick Response Code Article Info:

\begin{tabular}{l} 
doi: 10.5866/2019.11.10017 \\
$\begin{array}{l}\text { Received: 06-01-2019 } \\
\text { Revised: 07-02-2019 } \\
\text { Accepted: 04-03-2019 } \\
\text { Available Online: 01-04-2019, (www. } \\
\text { nacd.in)( NAD, 2019 - All rights } \\
\text { reserved }\end{array}$ \\
\hline
\end{tabular}

complications including pericoronitis, regional pain, dentoalveolar abscess, trismus, distal caries on the second molar, cysts, tumors, and dental arch crowding. ${ }^{[1]}$ The surgical removal of these impacted third molars may lead to various post-operative side effects including pain, swelling, trismus, nerve injury, bleeding, and dry socket. ${ }^{[2]}$ Conventionally, impacted third molars are most often removed using rotary cutting instruments for bone removal. However, these are potentially injurious because they generate excessively high temperatures during bone drilling, which leads to marginal osteonecrosis, and can impair osseous regeneration and healing. The resultant injury is also associated with 
significant post-operative pain and edema. With the recent advances toward minimally invasive surgery, using piezoelectric device has gained favor, promising a greater precision of cuts, lesser tissue damage, and fewer post-operative sequelae. Both these techniques are commonly used, but only limited comparison has been made between them with regard to outcome and complications. The aim of the present study was to compare the piezosurgery with rotary techniques in terms of their intraoperative and post-operative effects.

\section{MATERIALS AND METHODS}

The present study was conducted at the Department of Oral and Maxillofacial Surgery, Kamineni Institute of Dental Sciences. A total of 20 patients were selected with asymptomatic impacted mandibular third molars within the age of 18-40 years. Only healthy patients between 18 and 40 years of age were included in the study. All patients who consented to participate in the study and having vertical, mesioangular or horizontal, Class 2 or Class 3, and Level-B or Level-C lower third molar impactions were included in the study based on radiographic diagnosis. Patients with systemic diseases that could influence healing, patients with active infections requiring or currently using antibiotics, and those using analgesics or antiinflammatory products that could interfere with the post-operative assessments were excluded from the study.

Patients were subdivided into two groups randomly of 20 patients each in both the groups. Group A patients were treated with to rotary osteotomy technique and Group B patients were treated with piezoelectric osteotomy technique.

For pre-operative evaluation of patient, opening of mouth was evaluated with Vernier caliper, 5-point facial measurement was obtained with thread as baseline measurements for assessment of edema, and difficulty level of impacted third molar was recorded using WHARFE difficulty index. Radiographic examination was done using intraoral periapical radiograph/orthopantomography.

\section{Surgical Procedure}

Both Group A and Group B were treated by the same surgeon. Preoperatively, patients were given chlorhexidine mouthwash $0.2 \%$ for mouth rinsing, before giving $2 \%$ lignocaine local anesthesia with 1:80,000 adrenalin. The flap design of choice was either envelope or triangular modified wards incision. After flap reflection, in Group A, bone osteotomy was done by micromotor at 35,000 rpm using carbide round bur no. 6 and carbide straight fissure bur no. 702, and in Group B, bone osteotomy was done by piezosurgical unit using vibration frequency between 28 and $36 \mathrm{kHz}$ and using piezosurgical tips LC1 and LC2 [Figure 1].

Intraoperative assessment of the amount of tissue damage during removal of impacted mandibular third molar by both conventional rotary technique and piezoelectric technique and the assessment of surgery time in different types of mandibular third molar impactions was done. Postoperative assessment consisted of the comparison of post-operative pain evaluation, rated on visual analog scale (VAS) from day 0 to day 6 , trismus, evaluated by measuring the interincisal distance between incisal edge of upper and lower central incisors using a caliper at maximum mouth opening and swelling, and measured by assessment of the 5-point distance, from tragus to corner of the mouth, from tragus to chin, tragus to oral commissure, and angle to corner of the eye.

Statistical analysis was performed using Wilcoxon signed-rank test and t-test using IBM Statistical Package for the Social Sciences software (version 19; SPSS). $P<0.05$ was considered as statistically significant.

\section{RESULTS}

Duration of operation was calculated in each case from the start of incision till the termination of suturing. The mean time of surgery was 27.35

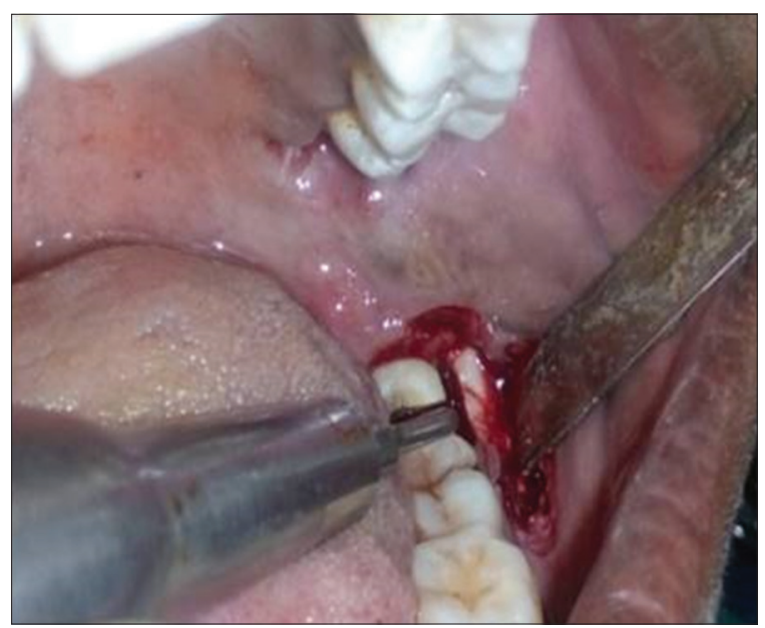

Figure 1: Clinical picture showing buccal bone guttering done with piezotome 
\pm (3.1) $\min$ in Group A, whereas it was $53.65 \pm$ (2.4) $\min$ in Group B. When comparing both groups regarding the surgical time, there was a significant statistical difference $(P=0.000)$ [Table 1].

Bone loss was observed along the distal aspect of the second molar within the two groups, and a significant greater amount of bone loss was noticed in Group A when compared to Group B. The mean incidence of tissue destruction was $0.8000 \pm(.41039)$ in Group A, whereas it was $0.2000 \pm(.41039)$ in Group B. When comparing both groups regarding the tissue destruction, there was a statistically significant difference $(P=0.001)$ [Table 2].

The mean post-operative pain on days $0,3,5$, and 7 [Table 3] shows lower immediate post-operative pain in Group B compared to Group A as well as an earlier total relief from pain in Group B compared to Group A. The difference in pain between the two groups, both in the immediate post-operative period and on the $5^{\text {th }}$ post-operative day was found to be statistically significant $(P<0.05)$.

The mean maximum mouth opening recorded on day 3 in Group A and Group B was $24.35 \pm$ (1.39) and $30.40 \pm(1.23)$, respectively. On day 5 , the mean mouth opening was $34.3 \pm(1.6)$ in Group A and $40.65 \pm$ (1.18) in Group B. The difference in mouth opening between both groups on both days was found to be statistically significant $(P<0.05)$.

Table 1: Duration of surgery in Group A and Group B

\begin{tabular}{llll}
$\begin{array}{l}\text { Surgical } \\
\text { time (min) }\end{array}$ & Group A & Group B & P value \\
\hline Mean & $27.35 \pm 3.0 \mathrm{~min}$ & $53.65 \pm 2.3 \mathrm{~min}$ & 0.000 \\
\hline
\end{tabular}

* $P<0.05$ is considered as statistically significant

Table 2: Tissue destruction in Group A and Group B

\begin{tabular}{lccc}
$\begin{array}{l}\text { Tissue } \\
\text { destruction }\end{array}$ & Group A & Group B & Pvalue \\
\hline Mean & $0.8000 \pm 0.41039$ & $0.8000 \pm 0.41039$ & 0.001 \\
\hline$* P<0.05$ is considered as statistically significant &
\end{tabular}

Table 3: Post-operative pain in Group A and Group B

\begin{tabular}{lcc} 
Post-operative pain & Group A & Group B \\
\hline Day 0 & $5.05 \pm(0.69)$ & $3.05 \pm(0.69)$ \\
Day 3 & $3.20 \pm(0.69585)$ & $1.50 \pm(0.69)$ \\
Day 5 & $2.0 \pm(0.72548)$ & $0.40 \pm(0.6)$ \\
Day 7 & $0.70 \pm(0.73270)$ & 0 \\
\hline
\end{tabular}

On the $3^{\text {rd }}$ post-operative day, mean postoperative swelling was $2.51 \pm(0.3) \mathrm{cm}$ in Group A and mean post-operative swelling was $1.2600 \pm$ $(0.28910) \mathrm{cm}$ in Group B. On the $5^{\text {th }}$ post-operative day, mean post-operative swelling was $1.4 \pm(0.31)$ in Group A and $0.5650 \pm(0.21095)$ in Group B. The difference in swelling between both groups on the $3^{\text {rd }}$ day was found to be statistically significant.

\section{DISCUSSION}

A tooth is said to be impacted when its path of eruption into the occlusal plane is obstructed by the presence of another tooth, bone, or soft tissue so that its further eruption is unlikely. Several therapeutic protocols have been evaluated to decrease the post-operative complications of surgical removal of impacted tooth ranging from medication to operative procedure. Bone removal has been attempted by chisel and mallet, high- or low-speed rotary instruments, and piezoelectric device in an attempt to alleviate the post-operative complications.

Rotary handpiece is used for surgical extraction of impacted third molar mainly. Surgical straight handpiece connected to a micromotor would be utilized for bone cutting with the aid of external saline irrigation. Rotary speed of straight handpiece is about 25,000 - 35,000 RPM. ${ }^{[1]}$

The piezoelectric technique was tested in oral surgery during the 1970s when Horton et al. examined the recovery process of dogs that had undergone osteotomy. Piezo devices use a modulated ultrasonic frequency that permits bone cutting with microvibration. It works selectively, being inert against soft tissues including nerves and blood vessels, a significant advantage compared with bur. Piezoelectric surgery was reevaluated definitively at the end of the 1980s, and today, it is considered an alternative technique that can be used in osseous oral and maxillofacial surgery, as it also produces fewer post-operative complications. ${ }^{[2]}$

The present study was done to evaluate intraoperative time, tissue destruction, postoperative swelling and pain, and other inflammatory events after the surgical removal of impacted third molar by piezoelectric device and conventional rotary instruments. The difference between the two groups was assessed with various parameters such as surgical time, tissue (bone) destruction, post-operative pain, post-operative swelling, and trismus. 


\section{Surgical Time}

Duration of procedure was calculated in each case from the start of incision till the completion of suturing. In the present study, the mean time of surgery was 27.35 min in Group A (rotary), whereas it was 53.65 min in (piezoelectric) Group B. Hence, impaction done by the piezoelectric unit was more time consuming then impaction done by rotary. The mean difference between the time period for surgical removal between piezoelectric unit and rotary unit was $25 \mathrm{~min}$. The present study coincides with the randomized control trial conducted by Barone et al. on 26 patients who required lower third molar extraction. The mean time necessary for flap elevation, bone removal, and tooth extraction with the use of rotary instruments was $30.5 \pm$ $4.4 \mathrm{~min}$, whereas with the piezoelectric device, it was $34.3 \pm 7.4 \mathrm{~min}$ although the time difference in our study was much greater. ${ }^{[3]}$ A meta-analysis conducted by Al Moraissi et al. according to their results, they concluded that the duration of surgery and operating time for the third molar extraction were significantly shorter with conventional rotary instruments compared to the piezoelectric surgical technique. ${ }^{[4]}$

The difference in duration is attributed to both the faster cutting speeds of rotary instruments and the counter-intuitive unfamiliar usage of the piezosurgical unit.

\section{Tissue Destruction}

Bone loss along the distal aspect of the second molar was subjectively observed and noted within the two groups as adequate and excessive compared to what was deemed to be the minimum bone removal required to deliver the tooth in each case. Most patients in Group A (16 of 20 patients) showed what was assessed to be excessive bone destruction compared to Group B which showed 4 of the 20 patients with excessive bone destruction. The difference of the mean incidence of excessive bone destruction in both groups was seen to statistically significant $(P=0.001)$. Basheer et al. conducted the study to assess and compare the surgical and postsurgical outcomes of the third molar removal using piezoelectric surgery and rotary bur. They concluded that piezosurgery method reduces post-operative complications, and it may play an important role in decreasing the amount of bone loss of adjacent tooth in the distal aspect. ${ }^{[1]}$ Literature shows that one of the biggest advantages of piezosurgery is the precision of the cut. The piezosurgery works on a principle of microvibrations which gradually chips of the bone in the precise location of the application of the blade. Whereas rotary instruments, during rotation, result in macrovibrations that can affect the operators grip and the path of the osteotomy cut.

\section{Pain, Swelling, and Trismus}

Pain is the most common post-operative complication after surgical removal of impacted mandibular third molar and is caused by release of pain mediators from the injured tissues. It begins after the anesthesia subsides and reaches its peak level during the $1^{\text {st }}$ post-operative day. If dry socket or infection occurs, the onset of inflammation will complicate alleviation of post-operative pain. ${ }^{[5]}$ Pain was assessed during the post-operative periods with a VAS of 10 units.

On $0-3^{\text {rd }}$ post-operative days, pain was severe in Group A as compared to Group B while on the $7^{\text {th }}$ post-operative day, mild post-operative pain was there in control Group A and pain was almost nil in Group B. A study conducted by Mantovani et al. to investigate the performance of piezosurgery compared with traditional rotating instruments during mandibular third molar removal, they observed that mean VAS in rotary group on the $2^{\text {nd }}$ post-operative day was 6.09 , on the $4^{\text {th }}$ postoperative period was 3.41 , on the $6^{\text {th }}$ post-operative period was 1.27 , and mean VAS in piezoelectric group on the $2^{\text {nd }}$ post-operative day was 5.97 , on the $4^{\text {th }}$ post-operative period was 2.81 , and on the $6^{\text {th }}$ post-operative period was $0.82 .{ }^{[6]}$

On the assessment of trismus, the $3^{\text {rd }}$ postoperative day mean mouth opening was $24.35 \mathrm{~mm}$ in Group A and $30.40 \mathrm{~mm}$ in Group B. On the $5^{\text {th }}$ postoperative day, mean trismus $34.30 \mathrm{~mm}$ in Group A and $40.65 \mathrm{~mm}$ in Group B. Fatima et al conducted a study to find out the efficacy of piezoelectric device in impacted mandibular third molar surgery and noted greater trismus in the rotary group on $3^{\text {rd }}(3.18$ $\mathrm{cm})$ and $5^{\text {th }}$ (3.67) postoperative day, as compared to the peizosurgical group which was $3.88 \mathrm{~cm}$ on the $3^{\text {rd }}$ and $4.09 \mathrm{~cm}$ on the $5^{\text {th }}$ post-operative day and these results are in concordance with the present study. ${ }^{[7]}$

Swelling is a normal post-operative event following the surgical removal of impacted mandibular third molar. It is caused by the response of tissues to manipulation and trauma 
caused during surgery; its onset is gradual and maximum swelling is present during $48 \mathrm{~h}$ after injury. Regression of swelling is expected by the $4^{\text {th }}$ day and completely resolution occurs in 7 days. ${ }^{[8]}$ On the $3^{\text {rd }}$ and $5^{\text {th }}$ post-operative days, significant difference existed between mean measurements. At the $3^{\text {rd }}$ post-operative day, mean post-operative swelling was $2.51 \mathrm{~cm}$ in control Group A and mean post-operative swelling was $1.26 \mathrm{~cm}$ in Group B. At the $5^{\text {th }}$ post-operative day, mean post-operative swelling was $1.39 \mathrm{~cm}$ in Group A and mean postoperative swelling was $0.56 \mathrm{~cm}$ in Group B. A study conducted by Fatima et al. in which swelling after surgical extraction of impacted mandibular third molar done in rotary group on the $3^{\text {rd }}$ post-operative day was $4.21 \mathrm{~cm}$ and on the $5^{\text {th }}$ post-operative day was $3.84 \mathrm{~cm}$ and swelling after surgical extraction of impacted mandibular third molar done by piezoelectric device on the $3^{\text {rd }}$ post-operative day was $2.86 \mathrm{~cm}$ and on the $5^{\text {th }}$ post-operative day was $1.28 \mathrm{~cm}$. They concluded that swelling was less in patients undergoing surgical extraction of impacted third molar by piezoelectric device as compared with surgical extraction done by rotary handpiece which is similar to the present study. ${ }^{[7]}$

Pain, swelling, and trismus in a patient undergoing surgical removal of the third molar are associated with the extent of tissue injury. The relatively lower incidence and intensity of these complications in the piezosurgical group are due to lesser tissue damage cause in this group compared to those who underwent surgical removal by rotary instrumentation. In addition, the cavitation phenomenon, caused by implosion of gas bullae into blood vessels during osteotomy during piezosurgery, produces an important hemostatic effect to optimize intraoperative visibility, thus reducing accidental damage. In addition to the osteotomy instrumentation, extension of incision as well as tissue manipulation and length of surgery affect the entity of swelling. ${ }^{[2]}$ In surgeries for impacted third molar region, time of intervention thought to be associated with tooth position, angle, and experience of surgeon and these parameters determine the difficulty of surgery and related to post-operative swelling and other complications, longer surgical interventions thought to increase tissue damage and vascular permeability can cause post-operative edema and affect its intensity. ${ }^{[8]}$

\section{CONCLUSION}

Although piezosurgery is fast being adopted for major surgical procedures, its cost remains one of the major reasons for its continued limited usage in minor oral surgery like impacted third molar removal. However, the advantages to the patient comfort and improved prognosis in terms of postoperative complications make piezosurgery the better option even for the removal of impacted third molars.

\section{REFERENCES}

1. Basheer SA, Govind RJ, Daniel A, Sam G, Adarsh VJ Rao A, et al. Comparative study of piezoelectric and rotary osteotomy technique for third molar impaction. J Contemp Dent Pract 2017;18:60-4.

2. Sortino F, Pedullà E, Masoli V. The piezoelectric and rotatory osteotomy technique in impacted third molar surgery: Comparison of postoperative recovery. J Oral Maxillofac Surg 2008;66:2444-8.

3. Barone A, Marconcini S, Giacomelli L, Rispoli L, Calvo JL, Covani U, et al. A randomized clinical evaluation of ultrasound bone surgery versus traditional rotary instruments in lower third molar extraction. J Oral Maxillofac Surg 2010;68:330-6.

4. Al-Moraissi EA, Elmansi YA, Al-Sharaee YA, Alrmali AE, Alkhutari AS. Does the piezoelectric surgical technique produce fewer postoperative sequelae after lower third molar surgery than conventional rotary instruments? A systematic review and meta analysis. Int J Oral Maxillofac Surg 2016;45:383-91.

5. Jiang Q, Qiu Y, Yang C, Yang J, Chen M, Zhang Z, et al. Piezoelectric versus conventional rotary techniques for impacted third molar extraction: A meta-analysis of randomized controlled trials. Medicine (Baltimore) 2015; 94:e1685.

6. Mantovani E, Arduino PG, Schierano G, Ferrero L, Gallesio G, Mozzati M, et al. A split-mouth randomized clinical trial to evaluate the performance of piezosurgery compared with traditional technique in lower wisdom tooth removal. J Oral Maxillofac Surg 2014;72:1890-7.

7. Tasveer F, Gupta H, Kumar D. Peizoelectric ostectomy: A new technique for impacted third molar surgery. IOSR J Dent Med Sci 2015;14:103-7.

8. Darawade DA, Kumar S, Mehta R, Sharma AR Reddy GS. In search of a better option: Dexamethasone versus methylprednisolone in third molar impaction surgery. J Int Oral Health 2014;6:14-7. 